paper by H. H. Thomas and P. J. Askey describing work at the Liverpool Gas Co. on the production of reactive coke by alkali activation. For some years it has been known that a little sodium carbonate alters the mode of burning of carbon, making it blaze more freely. The quantity of alkali necessary can be replaced to a great extent by lime with a corresponding reduction of cost. The authors record results of a large-scale trial in which coal treated with $1 \cdot 25$ per cent lime and 0.5 per cent sodium carbonate was carbonized in normal gas retorts. The coke so produced over a period of seventeen months has been sold to Liverpool consumers for use in the fireplaces in normal use and to the general satisfaction. In ease of combustion the fuel compared favourably with low-temperature coke, with the advantage that it was made in standard gas-making plant at high temperature, without sacrifice of the yield and output of gas - factors of importance in ensuring economical working.

\section{Malaria in Costa Rica}

A. A. Guzmán discussed the problem of malaria in Costa Rica at the Eighth American Scientific Congress on May 17. Due to climatic variations because of altitude, malaria is distributed irregularly in Costa Rica, most of it being confined to the low coastal areas and the Nicaraguan frontier, although some high valleys are also infected. Since the greater part of the inhabitants live on the high central plateau, in the cities of Alajuela, Cartago, Heredia and San José, the incidence of malaria is lower than would otherwise be expected. In 1938 and part of 1939 more than 9,000 primary school children in 168 localities were examined for spleen enlargement, the results indicating that six times as much malaria occurred in areas less than 1,000 ft. above sea-level as in higher regions. Blood smears from every child with splenic enlargement, and from one third of the rest, were examined microscopically, 3,981 smears from 9,226 children (43 per cent) being examined. Giemsa stain was used. $P$. vivax and $P$. falciparum were found throughout the malaria region; $P$. malarice was most common on the Pacific coast and in the Province of Guanacaste.

The scarcity of funds for malaria control work resulted in a decision to begin by carrying out permanent work in two localities, and proceed on the basis of an annual appropriation to carry forward the work of draining centres of population, before attempting to deal with malaria in rural areas. The work was begun in 1939 in Liberia, capital of the province of Guanacaste, which had the highest splenic index among school children, with the installation of drainage ditches made of pre-cast concrete sections as used by Dr. D. P. Curry in the Panama Canal zone. At the same time the town of Las Cañas, similar in conditions to Liberia, was left unsanitated as a control. The splenic index in Liberia was reduced to one fourth of the original figure; that in Las Cañas remained unchanged. Drainage work was then begun in Las Cañas in 1940. During 1939, 6,908 concrete inverts, 9,573 side slabs, and 145 sections of concrete pipe were made in the Liberia shop. By December 1939 slightly more than $4 \mathrm{~km}$. of ditch had been laid in the Liberia area, at a total cost, including heavy equipment, of approximately 18,600 dollars, to which the Costa Rican Government contributed about 87 per cent and the Rockefeller Foundation 13 per cent.

\section{Exposure to Fluorine in Industry}

W. Machle and E. E. Evans (J. Indust. Hyg. and Toxicol., 22, 213 ; 1940) have reviewed the literature on the effect of industrial exposure to fluorine and record the following personal observations. They found that five years of intermittent exposure to concentrations of fluorine which were harmful to rabbits and monkeys were tolerated by a group of industrial workers without clinical or röntgenological evidence of damage and without injury to the blood as shown by hæmatological examination. Comparative examinations showed them that the exposure of the workers resulted in the absorption of more than three times the normal amount of fluorine. Experiments on animals indicated that this continuous absorption would result in the deposit of abnormally large amounts of fluorine in the teeth and bones, but clinical evidence of this kind has not yet appeared.

\section{Pre-Columbian Burial in Panama}

As archæological expedition to Panama of the University Museum of the University of Pennsylvania, under the leadership of Dr. J. Alden Mason, has discovered the tomb of a chief or official in which the intrinsic value of the personal ornaments recalls the stories of the early Conquistadores of the wealth of the Central American caciques in precious metal, to which the finds of Dr. Alfonso Caso on Monte Alban in Mexico have also borne eloquent testimony. The find was described by Dr. Mason in a first report of the expedition before the Eighth American Scientific Congress in Washington, D.C. He described the burial, it is stated in a brief report circulated by Science Service, as a pit $11 \mathrm{ft}$. deep. In it had been laid the body of the chief, "resplendent . . . in shining gold". His ornaments included gold cuffs and anklets, great shining disks of this metal ornamenting his clothing, golden ear-clips, bells, and beads. From layers of broken pottery, Dr. Mason concludes that the mourners must have danced on or trampled pottery into the grave in some burial rite. This discovery was made in a vegetation-covered graveyard on a plantation in Coclé Province, one hundred miles west of Panama City. The origin of the people responsible for the burial has not yet been determined; but the culture differs from that of both Maya and Aztec and points to South rather than North American affinities. The find is dated as belonging to the period 1300-1500 of our era.

\section{Australia's Electrical Requirements}

AN Australian correspondent writing in the Electrical Times of August 22 says that the rapid expansion of secondary industries in Australia has been particularly noticeable in the production of electrical machinery, equipment and appliances to 